\title{
Long-term survival of patients with unoperated single ventricle heart : case reports and literature review
}

\author{
Shengnan Zhao ${ }^{1}$, Jiantao Guo ${ }^{1}$, Zhixia Sun $^{1}$, and Tingting Cui ${ }^{1}$ \\ ${ }^{1}$ Affiliation not available
}

May 1, 2021

\begin{abstract}
A single ventricle (SV) heart defect is a rare complex congenital cardiac malformation. We followed up the four adult patients who had SV since birth without surgical intervention and they had a good prognosis. The common ultrasound characteristics of four long-term SV survivors were investigated by reviewing their medical records and the literature, and the current treatment methods for SV patients were also reviewed. In our opinion,such patients with balanced hemodynamic condition should be followed and treated conservatively. This report aims to improve the prognosis as well as quality of life of SV patients.
\end{abstract}

\section{Introduction}

A single ventricle (SV) heart defect is a rare complex congenital cardiac malformation, accounting for approximately $1 \%-2 \%$ of congenital heart diseases. ${ }^{1} \mathrm{SV}$ is more commonly referred to as two-sided atrioventricular valves or a common atrioventricular valve opening in one ventricle. Patients with SV have only one functional ventricular chamber, and blood from the body and pulmonary circulation is mixed in the heart chamber, often causing overload in the single functional ventricular chamber and leading to heart failure in the early stages. ${ }^{2}$ Surgical intervention is the mainstay treatment for SV patients, although patients who do not receivesurgical intervention may also survive. For example, it was reported that among unoperated patients with single-ventricular hearts, the first-year survival rate was 10 percent to 30 percent, with a median survival of 14 years. ${ }^{3}$ In this study, we report four adult patients who had SV since birth without surgical intervention and survived to adulthood. All the case information and the images (Figures 1-4) in this review have been approved by the ethics committee of our hospital.We also conducted a Medline search and reviewed similar cases published in recent years. In addition, we summarized the influence of treatment methods on the survival rate of SV patients in recent years.

\section{Case reports}

\section{Case 1}

A 13-year-old female patient (height:150 cm; weight: $42 \mathrm{~kg}$ ) was diagnosed with functional SV combined with transposition of the great arteries (TGA) with a right position of the aorta based onultrasound findings at the age of 3, but did not receive any treatment. In 2017, she came to our hospital due to numbness in both lower limbs and dyskinesia. Thoracic magnetic resonance imaging (MRI) showed a space-occupying lesion in the spinal canal. A bone biopsy was performed and revealed cavernous hemangioma. This patient underwent a tumor resection at another hospital and returned to our hospital for radiotherapy 5 months after the operation.

Physical examination at our hospital showed a temperature of 36.5 , a pulse of 80 beats $/ \mathrm{min}$, no difference in the pulse and heart rate (HR), a respiratory rate of 18 breaths $/ \mathrm{min}$, and a blood pressure of 120/80 mmHg.Other pertinent examinations showed no signs of anemia and she had no history of hemoptysis, 
syncope, or long-term high fever. The patient exhibited normal development, moderate nutrition, and a clear mind. Her New York Heart Association functional class was II. Echocardiography revealed the following: the heart was located in the left thoracic cavity, the atrium was in the normal position, the left ventricular cavity was the main cavity, and the right ventricular cavity was the residual cavity. The pulmonary artery (PA) was locatedon the posterior sideand arose from the autonomous cavity. The aorta was moderately developed, located on the anterior sideand arose from the self-mutilating cavity. Echocardiography at the upper interventricular septum was interrupted by $22.3 \mathrm{~mm}$ (Figure 1). Color Doppler flow imaging (CDFI) revealed a two-way low-resistance shunt in the ventricular septal defect. The patient was diagnosed with the following diseasesbased on the echocardiography results: congenital heart disease, functional SV, TGA, mild PS, left ventricular hypertrophy, and left atrial enlargement. Further examination was recommended. No tumor metastasis was found after radiotherapy at our hospital and the prognosis was appreciable.

\section{Case 2}

A 41-year-old female patient (height: $163 \mathrm{~cm}$, weight: $53 \mathrm{~kg}$ ) was admitted to our hospital due to chest pain, chest tightness, and palpitations lastingfor 3 days. She presented with cyanosis of the mouth and limb immediately after birth, with obvious cyanosis after crying but without syncope or squatting signs. She was diagnosed with a congenital heart disease at the local hospital but was not treated. Her growth and development were not affected and daily activities were only slightly limited. After catching a cold 3 days earlier, she experienced chest tightness and shortness of breathafter general physical activities. After symptomatic treatment at the local hospital, she was admitted to our hospital due to a lack of obvious symptom relief.

Physical examination at our hospital revealed a temperature of 36.6, a pulse of 62 beats $/ \mathrm{min}$, a respiratory rate of 20 breaths/min, a blood pressure of $110 / 60 \mathrm{mmHg}$,clear consciousness, no yellowing of the skin and sclera, and cyanosis of the mouth. In addition, the breath sounds in both lungs were labored and moist rales could be heard in both lungs.Her heart rate was 62 beats/min, the heart rhythm was uniform, and her abdomen was flat and soft, without tenderness, rebound tenderness, or muscle tension. Her New York Heart Association functional class was III. Echocardiography showed visceral antipositioning and dextrocardia as well as a heart with a functional single atrium and SV, ventricular hypertrophy, and a common atrioventricular valve. The atrial and ventricular septa were not explored but wereclearly defined. Two large arteries, the PA and the aorta, were concomitant, both starting from thefunctional SV. The PA was located on the anterior side, the inferior valve had muscular stenosis, and the aorta was located on the posterior side. No obvious abnormalities were found in the aortic valve. CDFI revealed severe reflux in the common atrioventricular valve in the systolic stage, the neck of the valve orifice reflux was $13.4 \mathrm{~mm}$, the flow rate was $4.0 \mathrm{~m} / \mathrm{s}$, and the pressure gradient (PG) was $63 \mathrm{mmHg}$ (Figure 2). Under three-dimensional ultrasonic examination, the atrioventricular valves appeared to consist of four valves. The echocardiographic diagnosis for this patient was congenital heart disease complex deformity, dextrocardia, single atrium, SV, PS, and severe common atrioventricular valve insufficiency. The patient was discharged after 5 days of anti-infection and symptomatic treatments. After discharge, we continued to follow up with the patient by telephone and outpatient visits.

\section{Case 3}

A 13-year-old female patient (height: $137 \mathrm{~cm}$; weight: $40 \mathrm{~kg}$ ) came to our hospital due to palpitations and chest tightness lasting for 2 days. She was diagnosed with a complex congenital heart disease at the age of 6 months but was not treated. Physical examination on admission showed a body temperature of 36.4, a pulse of 57 beats $/ \mathrm{min}$, a respiratory rate of 21 breaths/min, and a blood pressure of 105/70 $\mathrm{mmHg}$. Her New York Heart Association functional class was II. Echocardiography showed the following: the heart was located in the left thoracic cavity, the atrium was in the normal position, the PA and the aorta were concomitant, and the PA was located in front of the aorta, both starting from a functional SV. The right atrium was enlarged, no atrioventricular valve was found in the left ventricular cavity parallel to the right atrium, the middle echo of the interventricular atrium was interrupted by $10.2 \mathrm{~mm}$, and the internal diameter of the $\mathrm{SV}$ was $65 \mathrm{~mm}$. CDFI showed a shunt in the atrial septal defect with a flow rate of $2.6 \mathrm{~m} / \mathrm{s}$ and a PG of 
$29 \mathrm{mmHg}$. Therewere severe reflux in the atrioventricular valve in the systolic stage, the regurgitation area of the atrioventricularvalve orifice was $3.7 \mathrm{~cm}^{2}$, the flow rate was $5.4 \mathrm{~cm} / \mathrm{s}$, and the $\mathrm{PG}$ was $117 \mathrm{mmHg}$ (Figure 3). The length of the pulmonary valve regurgitation beam was $22.8 \mathrm{~mm}$, the flow rate was $3.5 \mathrm{~m} / \mathrm{s}$, the PG was $50 \mathrm{mmHg}$, and the average PA pressure was estimated to be $55 \mathrm{mmHg}$. The echocardiographic diagnosis was congenital heart disease (SV,atrial septal defect), mild atrioventricular valve insufficiency, mild pulmonary valve regurgitation, and pulmonary hypertension (PHT). The patient was discharged after 3 days of symptomatic treatment.

\section{Case 4}

A 39-year-old woman (height: $162 \mathrm{~cm}$; weight: $57 \mathrm{~kg}$ ) came to our hospital for chest pain and chest tightness lasting for 4 days. She was diagnosed with a congenital heart disease at birth but was not treated. Physical examination on admission showed a temperature of 37.0, a pulse of 60 beats $/ \mathrm{min}$, a respiratory rate of 22 breaths/min, and a blood pressure of $110 / 80 \mathrm{mmHg}$. Her New York Heart Association functional class was II. Echocardiography showed the following: the heart was located in the left thoracic cavity, the atriumwas in the normal position, the positions of the PA and the aorta were abnormal, the aorta had widened and moved forward, and both the heart and PA started from the functional SV. A tortuous tube with no echo was seen between the left PA and the descending aorta, with a length of $15 \mathrm{~mm}$. There was noventricular septum, the internal diameter of the SV was $58.2 \mathrm{~mm}$ (Figure 4). CDFI revealed thatthe regurgitation area of the tricuspid valve orifice was $3.1 \mathrm{~cm}^{2}$, the flow rate was $4.1 \mathrm{~m} / \mathrm{s}$, and the $\mathrm{PG}$ was $66 \mathrm{~mm} \mathrm{Hg}$. The echocardiographic diagnosis for this patient was congenital heart disease (SV, left ventricular type, PHT, patent ductus arteriosus), and mild tricuspid regurgitation. The patient was discharged after 4 days of symptomatic treatment.

\section{Discussion}

SV heart defect is a rare congenital cyanotic heart disease often associated with PS, TGA, atrial septal defect, and other malformations. Echocardiography is the first choice for the diagnosis and evaluation of SV. Echocardiography can also be used to diagnose cardiac malformations in the early and second trimester of pregnancy, to make accurate judgments regarding the classification of SV, its associated malformations, and atrioventricular valve openings and reflux, as well as to evaluate ventricular function. ${ }^{4} \mathrm{SV}$ heart defects can be divided into four types according to the morphological structure: Type A, the left ventricular main chamber is dominant; Type B, the right ventricular main chamber is dominant; Type $\mathrm{C}$, the ventricular septum is absent, and the left and right ventricular structures constitute the ventricular cavity; and Type $\mathrm{D}$, indeterminate. ${ }^{5}$ Unlike echocardiography, three-dimensional ultrasound can visually display the internal structure of the heart, thus improving the accuracy of preoperative diagnosis, and is of great significance in the selection of surgical methods and the assessment of prognosis. ${ }^{6}$

We reviewed literature reports of SV heart defect cases involving patients over 13 years of age without surgical intervention and summarized the common characteristics that were correlated to the long-term survival of the patients (Table 1). The aforementioned four patients in this study were diagnosed with SV heart defects during childhood, but received no surgical intervention. All four patients had appreciable outcomes. Table 1 shows that the clinical manifestations and long-term prognosis of patients with SV heart defects primarily depend on the presence or absence of pulmonary blood flow obstruction, pulmonary vascular resistance, and ventricular shape and function. Whether the aortic blood flow is blocked and whether the shape and function of atrioventricular valve still function play an important role in patient prognosis. Moderate PS is critical for hemodynamic balance in SV patients; first, it restricts pulmonary blood flow and prevents pulmonary arteriole disease; second, it restricts the left-to-right shunt, prevents pulmonary blood flow increase and ventricular overload, and maintains sufficient pulmonary blood flow to supply oxygen. In addition, SV patients with adequate oxygenation and balanced ventricular load may have a chance for long-term survival. The morphology and function of the ventricles is another important factor. There are, in fact, no reports of long-term survival for patients with right morphology or an indeterminate-type SV. This is probably due to the intrinsic capacity of the left ventricle to deal with systemic resistance. When all other conditions are equal, patients with a single left ventricle heart defect have better prognosis than those with a single 
right ventricle heart defect. When aortic blood flow resistance increases, the ventricular afterload also increases, leading to a low cardiac output, which is not conducive to survival. In addition, effective and detached atrioventricular valves have a positive effect on survival. Atrioventricular valve dysfunction leads to ventricular volume overload. The optimal anatomical structure for SV patients is a normal morphology for the left ventricle, great artery displacement, no systematic obstruction of outflow tract, full atrioventricular valve function, and moderate PS. These anatomical features enable patients to survive mild to moderate symptoms and enjoy a good quality of life. It should also be noted that arrhythmias are the most common complications in older SV patients. ${ }^{7}$ With the improvement of surgical techniques and postoperative care, more SV patients have been able to survive for a longer period of time. The main treatment methods for SV patients are radical surgery, palliative surgery, and heart transplantation (Figure 5). The palliative surgery mainly includes modified Blalock-Taussig (B-T) shunt operation, PA banding, Norwood operation, Glenn operation, and Fontan operation. ${ }^{8}$

\section{Radical surgery}

Ventricular shunt is the earliest radical surgery that can be performed on SV patients. However, due to the limited number of patients suitable for radical surgery, the high rate of surgical mortality and total atrioventricular block, radical surgery is rarely performed.At present, radical surgery is only applicable to patients who have left ventricular SV with left aortic transposition, atrioventricular valves on both sides, and no other heart malformations. ${ }^{9}$

\section{Palliative surgery}

\subsection{B-T shunt}

Dr. Alfred Blalock created the B-T shunt operation in 1948 with the support of pediatric cardiologist Helen B Taussig and surgical technician Vivien Thomas. For patients with pulmonary obstruction, pulmonary dysplasia, and severe hypoxia, the B-T shunt operation can be performed to improve pulmonary circulation and promote pulmonary vascular development. After 6 months of age, pulmonary vascular resistance and PA development may be evaluated to determine the feasibility of a bidirectional Glenn operation. ${ }^{10}$

\subsection{PA banding}

For patients with restricted pulmonary circulation, a pulmonary loop surgery should be performed within 2 3 months to protect the pulmonary vascular bed and prevent the development of pulmonary hypertension. ${ }^{11}$ If the PA pressure is satisfactorily reduced, a bidirectional Glenn operation may be performed after 6 months of age. ${ }^{12}$

\subsection{Norwood Operation}

Dr. Norwood developed a series of operations to treat fetuses with hypoplastic left heart syndrome (HLHS) and achieved appreciable outcomes. Since then, Norwood's operation has been widely adopted with great success worldwide. ${ }^{13}$ Norwood's techniqueis one of the effective treatments for HLHS and left ventricular outflow tract obstruction complicated by SV. The Norwood operation contains three phases: phase I consists of palliative care with Norwood-type surgery in the neonatal period, phase II consists of a Glenn operation, and phase III consists of a full lumen operation. ${ }^{15}$

\subsection{Glenn Operation}

Dr. Glenn performed the first superior vena cava-right PA anastomosis for tricuspid regurgitation in $1958 .^{15}$ The bidirectional Glenn operation is a form of bidirectional superior vena cava pulmonary anastomosis, in which the proximal end of the superior vena cava is cut off, sutured, and closed, and the distal end has an end-to-side anastomosis with the right PA. If the left superior vena cava persists, the left superior vena cava and the left PA should be anastomosed at the same time. The Glenn operation is an important part of the series of palliative operations for SV treatment. It has been reported that the bidirectional Glenn operationfacilitates long-term remission in patients with a single functioning ventricle. ${ }^{16}$ 


\subsection{Fontan Operation}

It has been nearly 50 years since Dr. Fontan first described the Fontan operation in $1971 .{ }^{17}$ The traditional Fontan operation is performed by connecting the right atrium to the PA, suturing the tricuspid valve, and directly draining the vena cava blood to the lung. At present, the traditional Fontan operation is rarely used. A modified Fontan operation that consists of caval-pulmonary anastomosis was introduced and involves the intracardiac tunnel, intracardiac duct, and extracardiac total lumen-PA connection. At present, the most common clinical application of this technique is the extracardiac conduit of total cavopulmonary connection (ECTCPC). This surgical approach reduces the need for anoperation in the right atrium, avoids high right atrial pressure, and eventually reduces the incidence of early and mid-term arrhythmia after other surgical procedures. ${ }^{18}$ The Fontan cycle is characterized by increased vena cava pressure, decreased non-pulsating pulmonary blood flow, decreased ventricular preload, and increased postload. ${ }^{19}$ However, in the long run, the Fontan circulation is a non-physiological state, in which patients' tolerance to exercise and hemodynamic response are compromised, which can lead to various complications and affect the long-term prognosis. ${ }^{20}$ Broad Fontan circulatory failure can be classified into three categories: ventricular dysfunction, systemic complications of Fontan physiology (such as plastic bronchitis and protein-loss bowel disease), and chronic Fontan circulatory failure. ${ }^{21}$ Additional complications associated with Fontan surgery include an increased risk of stroke, protein-loss bowel disease, and arrhythmia without survival improvements. ${ }^{16}$ Despite these potential complications, the Fontan series of operations is still a common and effective method for SV treatment. When the Fontan series of operations and medical treatments are ineffective, the only choice for SV treatment is heart transplantation.

\section{Heart transplantation}

SV patients who have partial right ventricular SV, high PA pressure, and cardiac insufficiency but cannot undergo palliative surgery can choose heart transplantation. The best time for a heart transplantation is after the Glenn operation but before the Fontan operation is completed.However, due to the limited number of donors, heart transplantation is not widely performed. ${ }^{23}$

\section{Drug treatment}

The level of pulmonary vascular resistance in SV patients is the key to determine the long-term postoperative efficacy. ${ }^{24}$ Nine drugs have been approved in North America and Europe for the treatment of pulmonary hypertension. These drugs fall into four categories: 5-phosphodiesterase (PDE-5) inhibitors, endothelin receptor antagonists, prostacyclin analogues, and soluble guanosine activators. In recent years, pulmonary vascular targeted drugs such as Sildenafil and Bosentan have also been used in the perioperative treatment of Fontan patients. One case report showed that Sildenafil improved the outcomes for patients with proteinlosing bowel disease, ${ }^{25}$ while in another,Sildenafil was used to treat plastic bronchitis. ${ }^{26}$ A new study showed that a single dose of Sildenafil improved the peak exercise performancein Fontan patientscompared with a placebo. ${ }^{27}$ On the other hand, there is little evidence to support the use of angiotensin-converting enzyme (ACE) inhibitors for SV patients. ${ }^{28}$

\section{Conclusion}

With the development of new surgical methods for the treatment of SV heart defects, it is important to understand the long-term outcomes for patients who have not been operated on. ${ }^{29}$ While the Fontan operation has become a common and effective method for SV treatment, long-term outcomes are fraught with morbidity and mortality. The majority of patients in our series and in the literature to demonstrate advanced survival had DILV and PS.In our opinion,such patients with balanced hemodynamic condition should be followed and treated conservatively. Major cardiac surgery which leads to gross hemodynamic adjustments should be avoided. ${ }^{30}$ The optimal timing for surgery and appropriate surgical method can be determined based on: 1) the patient's symptoms and specific diagnosis of SV heart defect, and 2) the following conditions: the anatomy of the parting and concurrent heart malformations, the development of the PA, the amount of pressure and resistance, and ventricular function, with a significant aim to reduce mortality and improve the prognosis as well as quality of life of SV patients. 


\section{Acknowledgement}

We express our deepest gratitude to Hui Wang, for his guidance.

\section{Declaration of conflicting interests}

There are no conflicts of interest.

\section{Funding Sources}

The author(s) received no financial support for the research, authorship, and/or publication of this article.

\section{References}

1. Boukhris M, Hakim K, M'saad H, et al. Successful pregnancy and delivery in a woman with a single ventricular and Eisenmenger syndrome. Journal of the Saudi Heart Association.2013;25(4): 261-4.

2. Kana Wang,Hong Luo, Yalan Xin,et al. Successful pregnancy and delivery in patients with uncorrected single ventricular: Three new cases and literature review . Int J Cardiol. 2015;184:135-9.

3. Hager A, Kaemmerer H, Eicken A, et al. Long-term survival of patients with univentricular heart not treated surgically. J Thorac Cardiovasc Surg.2002 Jun;123(6): 1214-7.

4. Wiechec M, Knafel A, NocunA. Prenatal detection of congenital heart defects at the 11- to 13-week scan using a simple color Doppler protocol including the 4-chamber and 3-vessel and trachea views.J Ultrasound Med,2015;34(4):585-94.

5. de Siena P, Ghorbel M, Chen Q,et al. Common arterial trunk: review of surgical strategies and future research. Expert review of cardiovascular therapy. 2011 Dec; 9(12): 1527-38.

6.Adriaanse B M E, van Vugt J M G, Haak M C. Application value of three-section echocardiography in diagnosis of congenital heart disease. J Perinatol,2016 Sep;36(9):685-93.

7. Hager A, Kaemmerer H, Eicken A, et al. Long-term survival of patients with univentricular heart not treated surgically. J Thorac Cardiovasc Surg.2002 Jun;123(6):1214-7. PubMed PMID:12063473.

8. Davies R R, Pizarro C. Decision-Making for Surgery in the Management of Patients with Univentricular Heart.Front Pediatr,2015 Jul 27;3:61.

9. JONAS R A. Fontan or septation: when I abandon septation in complex lesions with two ventricles . Semin Thorac Cardiovasc Surg Pediatr Card Surg Annu.2009;94-8.

10. Toledo-Pereyra L H.Surgeon, Educator, and Pioneer in Shock and Cardiac Research. Investigative Surgery.Jul-Aug .2005;18(4):161-5.

11. Trusler GA, Mustard WT. A Method of Banding the Pulmonary Artery for Large Isolated Ventricular Septal Defect With and Without Transposition of the Great Arteries. Ann Thorac Surg.1972 Apr;13(4):3515 .

12. B. Alsoufi, S. Gillespie, B. Kogon, B, et al.Results of palliation with an initial modified Blalock-Taussig shunt in neonates with single ventricle anomalies associated with restrictive pulmonary blood flow. Ann Thorac Surg, 99 (2015), pp. 1639-1646.

13. Norwood WI, Lang P, Casteneda AR, Campbell DN. Experience with operations for hypoplastic left heart syndrome. The Journal of thoracic and cardiovascular surgery. 1981 Oct;82(4):511-9.

14. Brian $\mathrm{C} H$ Gulack, Obinna O Adibe. Laparoscopic antireflux surgery in infants with single ventricle physiology: a review.J Laparoendosc Adv Surg Tech A. 2013 Aug;23(8):733-7.

15. G W W. Circulatory bypass of the right side of the heart. IV. Shunt between superior vena cava and distal right pulmonary artery; report of clinical application. The New England journal of medicine, 1958, 259(3): 117-20. 
16. Day RW, Etheridge SP, Veasy LG,et al.single ventricular palliation: greater risk of complications with the Fontan procedure than with the bidirectional Glenn procedure alone. Int J Cardiol. 2006 Jan 13;106(2):20110.

17. Fontan F, Baudet E. Surgical repair of tricuspid atresia. Thorax. 1971 May;26(3):240-8.

18. Nakano T, Kado H, Tatewaki H,et al. Results ofextracardiac conduit total cavopulmonary connection in 500 patients. European journal of cardio-thoracic surgery: official journal of the European Association for Cardio-thoracic Surgery.2015;48(6):825-32.

19. Clift P F. The Fontan circulation: An alternative physiology, Int J Cardiol,2018;257:76-77.

20.Valente A M, Lewis M, Vaziri S M , et al. Outcomes of Adolescents and Adults Undergoing Primary Fontan Procedure. The American Journal of Cardiology.2013 Dec15;112(12):1938-42.

21. Goldberg D J, Shaddy R E, Ravishankar C, et al. The failing Fontan: etiology, diagnosis and management. Expert Review of Cardiovascular Therapy. 2011 Jun;9(6):785-93.

22. Kenny LA, DeRita F, Nassar M,et al. Transplantation in the single ventricle population. Ann Cardiothorac Surg. 2018 Jan;7(1):152-159.

23. Bacha EA. Individualized Approach in the Management of Patients With Hypoplastic Left Heart Syndrome (HLHS). Seminars in Thoracic and Cardiovascular Surgery: Pediatric Cardiac Surgery Annual.2013; 16(1): $3-6$.

24. CILIBERTI P, SCHULZE-NEICK I, GIARDINI A. Modulation of pulmonary vascular resistance as a target for therapeutic interventions in Fontan patients: focus on phosphodiesterase inhibitors. Future Cardiol.2012 Mar;8(2):271-84.

25.Uzun O, Wong J K, Bhole V. Stumper O.Resolution of Protein-Losing Enteropathy and Normalization of Mesenteric Doppler Flow With Sildenafil After Fontan. The Annals of Thoracic Surgery.2006 Dec;82(6):e3940.

26. Haseyama K, Satomi G, Yasukochi S, et al. Pulmonary vasodilation therapy with sildenafil citrate in a patient with plastic bronchitis after the Fontan procedure for hypoplastic left heart syndrome. The Journal of Thoracic and Cardiovascular Surgery.2006 Nov;132(5):1232-3.

27. Giardini A, Balducci A, Specchia S, et al. Effect of sildenafil on haemodynamic response to exercise and exercise capacity in Fontan patients. European Heart Journal.2008 Jul;29(13): 1681-7.

28. Wilson T G, Iyengar A J, d'Udekem Y. The Use and Misuse of ACE Inhibitors in Patients with single ventricular Physiology.Heart Lung Circ.2016 Mar,;25(3): 229-36.

29. Moodie D S, Ritter D G, Tajik A J, et al. Long-term follow-up in the unoperated univentricular heart. Am J Cardiol. 1984 Apr 1;53(8):1124-8.

30.Ammash N M, Warnes C A. Survival into adulthood of patients with unoperated single ventricle. The American Journal of Cardiology.1996, 77(7): 542-4.

31. Warner K G, Payne D D, Fulton D R .Excision of a pulmonary valve abscess in a 61-year-old woman with single ventricle. Ann Thorac Surg,1996;61(1):213-5.

32. Gabbarini F. A 61-year-old man with Holmes' heart. Lancet,1999 Feb 20;353(9153):646.

33. Restaino G, Dirksen MS, de Roos A. Long-term survival in a case of unoperated single ventricle. Int J Cardiovasc Imaging,2004 Jun;20(3):221-5.34. Book W M, Vaccari C, McConnell M E. Exceptional survival: double inlet left ventricle presenting with aortic dissection.Int J Cardiol,2007 Mar 20;116(2):e65-7.

35. Park S-J, Kwak C H, Hwang J-Y. Long-term survival in double inlet left ventricle combined with pulmonary stenosis and parachute mitral valve: a rare case. Int Heart J,2007;48(2):261-7. 
36. Coats L, Runnett C, Satchithananda D K. Double outlet right atrium with coexisting double inlet left ventricle and concordant ventriculoarterial connections: a fascinating variant of the Holmes heart. Cardiol Young,2010 Oct;20(5):587-9.

37. Paul GK, Bari MS, Bari MA. Long-term survival in an un-operated single ventricle. Mymensingh Med J,2012 Jul;21(3):543-6.

38. Wang K, Luo H, Xin Y, et al. Successful pregnancy and delivery in patients with uncorrected single ventricle: Three new cases and literature review. Int J Cardiol,2015 Apr 1;184:135-139.

39. Gesuete V, Fabi M, Bonvicini M. A 74-year-old unoperated univentricular heart: the oldest reported survival. Cardiol Young,2016;26(4):805-7.

40. Güvenç O, Saygi M, Şengü FS. Double inlet left ventricle-ventriculoarterial discordance without surgical treatment. Pediatr Int,2016;58(6):509-511.

41. Alpat S, Demircin M. Living with functionally univentricular heart: beating the odds? Asian Cardiovasc Thorac Ann,2018;26(9):694-696.

42. Kongunattan K V, Ravi M S, Swaminathan N,et al. Single ventricle with infective endocarditis and brain abscess: A rare case report. J Indian Acad Echocardiogr Cardiovasc Imaging 2017;1:228-30.

43. Andrade P, Santos D, Moreira1 M, et al. Double-Inlet Single Ventricle with Malposed Great Arteries . Arq Bras Cardiol,2019 Oct 10;113(3):444-446.

Table 1. Reported unoperated SV patients with an age over 13 years

\begin{tabular}{|c|c|c|c|c|c|c|c|}
\hline References & $\begin{array}{l}\text { Published } \\
\text { time }\end{array}$ & Age /Sex & Anatomy & DILV & $\begin{array}{l}\text { NYHA } \\
\text { class }\end{array}$ & PHT & Arrhythmias \\
\hline $\begin{array}{l}\text { Warner et } \\
\mathrm{a}^{31}\end{array}$ & 1996 & $64 / \mathrm{F}$ & TGA & Yes & - & Yes & $1^{\circ} \mathrm{AVB}$ \\
\hline Gabbarinietal $^{32}$ & ${ }^{2} 1999$ & $61 / \mathrm{M}$ & MGA & Yes & II-III & Yes & $\begin{array}{l}\text { Paroxysmal } \\
\text { atrial } \\
\text { fibrillation }\end{array}$ \\
\hline $\begin{array}{l}\text { Hager et } \\
\text { al }^{3}\end{array}$ & 2002 & $62 / \mathrm{F}$ & TGA PS & Yes & III & Yes & $\begin{array}{l}\text { Atrial } \\
\text { fibrillation }\end{array}$ \\
\hline $\begin{array}{l}\text { Restaino } \\
\text { et } \mathrm{al}^{33}\end{array}$ & 2004 & $57 / \mathrm{F}$ & TGA & Yes & II & Yes & - \\
\hline $\begin{array}{l}\text { Book et } \\
\mathrm{al}^{34}\end{array}$ & 2007 & $71 / \mathrm{F}$ & TGA & Yes & - & Yes & NSR \\
\hline $\begin{array}{l}\text { Park et } \\
\mathrm{al}^{35}\end{array}$ & 2007 & $41 / \mathrm{M}$ & TGA & Yes & II-III & Yes & $\begin{array}{l}\text { Atrial } \\
\text { fibrillation }\end{array}$ \\
\hline $\begin{array}{l}\text { Coats et } \\
\mathrm{al}^{36}\end{array}$ & 2010 & $59 / \mathrm{F}$ & MGA & Yes & III & Yes & $\begin{array}{l}\text { Atrial } \\
\text { flutter }\end{array}$ \\
\hline $\begin{array}{l}\text { Paul et } \\
\mathrm{al}^{37}\end{array}$ & 2012 & $36 / \mathrm{M}$ & MGA & Yes & IV & Yes & $\begin{array}{l}\text { Atrial } \\
\text { fibrillation }\end{array}$ \\
\hline $\begin{array}{l}\text { Wang et } \\
\mathrm{al}^{38}\end{array}$ & 2013 & $35 / \mathrm{F}$ & MGA & Yes & II & Yes & NSR \\
\hline $\begin{array}{l}\text { Gesuete et } \\
\mathrm{al}^{39}\end{array}$ & 2016 & $74 / \mathrm{M}$ & TGA & Yes & II & Yes & $\begin{array}{l}\text { Atrial } \\
\text { flutter }\end{array}$ \\
\hline $\begin{array}{l}\text { Güvenç et } \\
\mathrm{al}^{40}\end{array}$ & 2016 & $31 / \mathrm{M}$ & TGA & Yes & III & Yes & NSR \\
\hline $\begin{array}{l}\text { Alpat et } \\
\mathrm{al}^{41}\end{array}$ & 2017 & $45 / \mathrm{M}$ & TGA & Yes & - & Yes & $\begin{array}{l}\text { Atrial } \\
\text { fibrillation }\end{array}$ \\
\hline $\begin{array}{l}\text { Kongunattan } \\
\text { et } \mathrm{al}^{42}\end{array}$ & 2017 & $27 / \mathrm{M}$ & TGA & Yes & - & No & - \\
\hline
\end{tabular}




\begin{tabular}{|c|c|c|c|c|c|c|c|}
\hline $\begin{array}{l}\text { Andrade } \\
\text { et al }\end{array}$ & 2019 & $62 / \mathrm{M}$ & TGA & Yes & - & Yes & - \\
\hline $\begin{array}{l}\text { Present } \\
\text { case } 1\end{array}$ & 2020 & $13 / \mathrm{F}$ & TGA & Yes & II & Yes & NSR \\
\hline $\begin{array}{l}\text { Present case } \\
2\end{array}$ & 2020 & $41 / \mathrm{F}$ & $\begin{array}{l}\text { PS Single } \\
\text { atrium }\end{array}$ & Yes & III & Yes & NSR \\
\hline $\begin{array}{l}\text { Present } \\
\text { case } 3\end{array}$ & 2020 & $13 / \mathrm{F}$ & $\begin{array}{l}\text { Atrial } \\
\text { septal } \\
\text { defect }\end{array}$ & Yes & II & Yes & NSR \\
\hline $\begin{array}{l}\text { Present case } \\
4\end{array}$ & 2020 & $39 / \mathrm{F}$ & $\begin{array}{l}\text { TGA Patent } \\
\text { ductus } \\
\text { arteriosus }\end{array}$ & Yes & III & Yes & NSR \\
\hline
\end{tabular}

$\mathrm{M}=$ male $\mathrm{F}=$ female DILV=double inlet left ventricle; $\mathrm{PHT}=$ pulmonary hypertension; $\mathrm{PS}=$ pulmonary stenosis; MGA=ventriculoarterial concordance with left/right position of the aorta; TGA=transposition of the great arteries with left/right position of the aorta; $\mathrm{AVB}=$ atrioventricular block; $\mathrm{NSR}=$ normal sinus rhyth

\section{Figure legends}

Figure 1. A 13-year-old female SV patient combined with cavernous hemangioma.Two-dimensional echocardiography: four-cavity cardiac surface view showing the left ventricular cavity was the main cavity, and the right ventricular cavity was the residual cavity. LA, left atrium; LV, left ventricle; RA, right atrium; RV, right ventricle

Figure 2. A 41-year-old female SV patient combined with single atrium. Two-dimensional echocardiography: four-cavity cardiac surface view showing a functional single atrium and a SV; CDFI showing severe reflux in the common atrioventricular valve in the systolicstage. A, atrium; V, ventricle

Figure 3.A 13-year-old female SV patient combined with atrial septal defect.A, Two-dimensional echocardiography: four-cavity cardiac surface view showing the right atrium was enlarged, no atrioventricular valve was found in the left ventricular cavity parallel to the right atrium. B,CDFI showing severe reflux in the atrioventricular valve in the systolic stage. LA, left atrium; $\mathrm{RA}$, right atrium; $\mathrm{V}$, ventricle

Figure 4.A 39-year-old female SV patient combined with patent ductus arteriosus. Two-dimensional echocardiography: four-cavity cardiac surface view showing two normal-sized atriums and an SV. LA, left atrium; $\mathrm{LV}$, left ventricle; $\mathrm{V}$, ventricle

Figure 5.Treatment methods for SV patients 

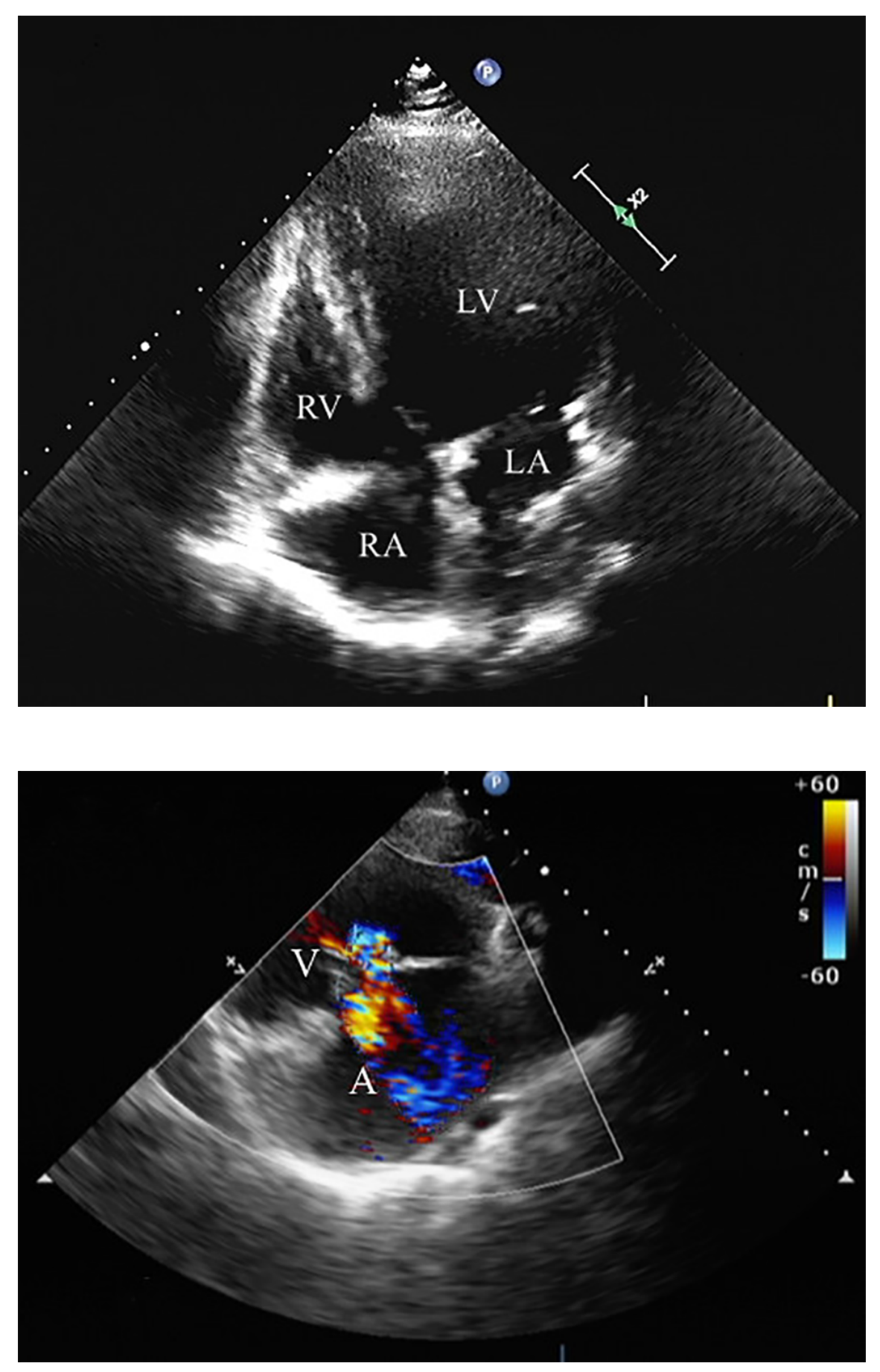

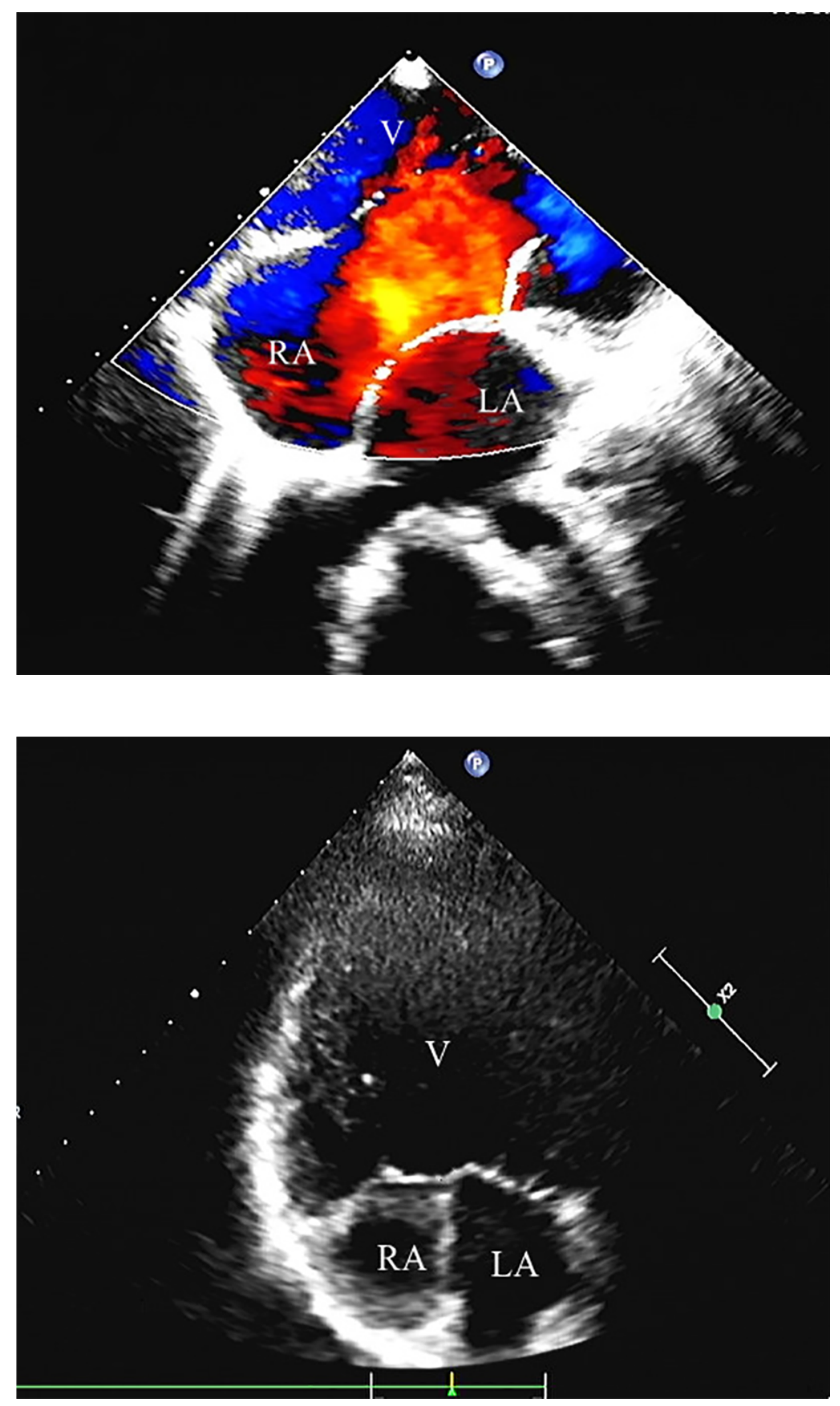


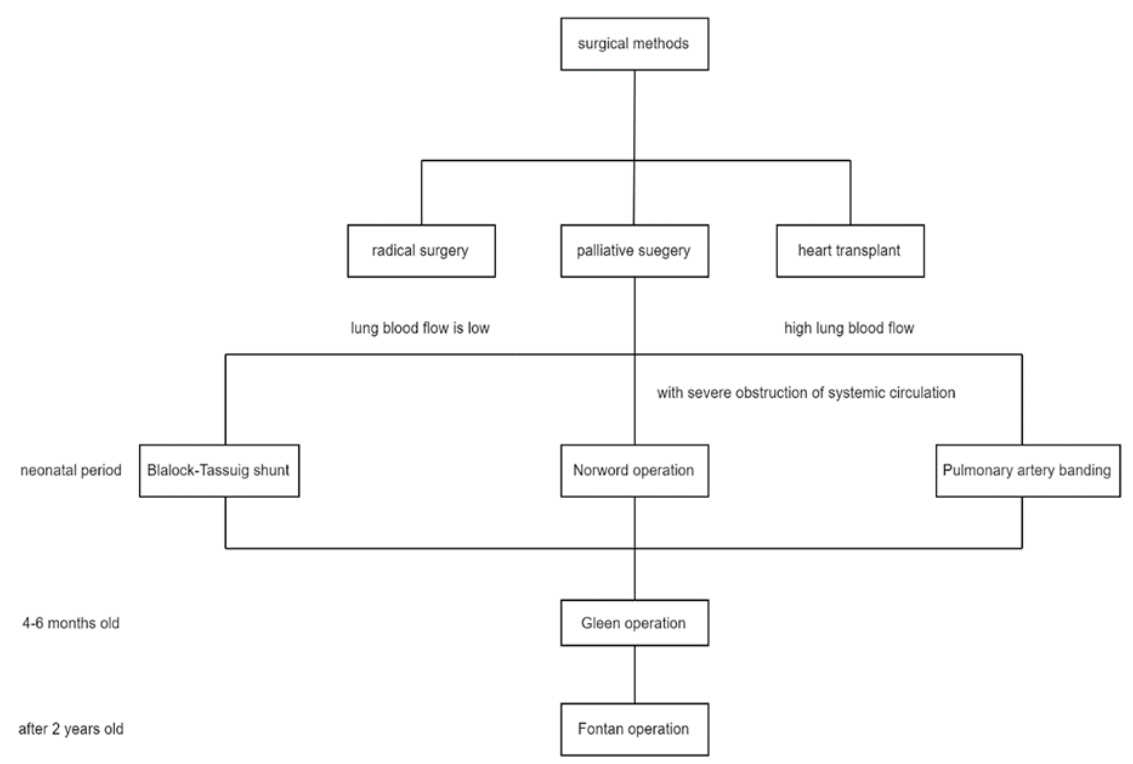

